\title{
HISTORIA URBANA EN LA GALICIA MEDIEVAL. BALANCE Y PERSPECTIVAS*
}

\section{URBAN HISTORY IN MEDIEVAL GALICIA. BALANCE AND PERSPECTIVES}

\author{
ÁLVARO SOLANO FERNÁNDEZ-SORDO \\ Becario JAE-Intro \\ Instituto de Estudios Gallegos "Padre Sarmiento" (CSIC-Xunta de Galicia)
}

\begin{abstract}
Resumen
En el marco de la Galicia medieval, a partir del siglo XI se asiste a un proceso de promoción de las realidades urbanas desde el poder real y los señoríos locales en un territorio tradicionalmente carente de ellas en los primeros siglos medievales. Éste ha sido objeto de estudio durante las últimas décadas, pero los últimos años han visto una proliferación de artículos y libros que hace necesaria una actualización historiográfica. El presente artículo expone este fenómeno de una madera diacrónica e informativa, incorporando las últimas publicaciones al respecto.
\end{abstract}

\section{Palabras clave}

Galicia, Plena Edad Media, ciudades, villas, historiografía.

\begin{abstract}
In the context of medieval Galicia, from the $\mathrm{XI}^{\text {th }}$ century we are witnessing a process of promoting urban realities since the real power and local domains in a territory traditionally devoid of them in the early medieval centuries. This has been studied in recent decades, but recent years have seen a proliferation of articles and books that requires an updating historiography. This paper discusses this phenomenon in a diachronic and informative way and incorporate the latest relevant publications.
\end{abstract}

\section{Keywords}

Galicia, XI-XIII ${ }^{\text {th }}$ centuries, cities, towns, historiography

\footnotetext{
* Recibido/Received 25.09.2009. Aceptado/Accepted 02.02.2010
} 
En el año 1007 el conde de Anjou Fulco III, llamado "el Negro", funda en Beaulie una abadía que confiará a monjes benedictinos y en cuya iglesia será enterrado. En este contexto, enviaría a sus oficiales en este territorio una carta que, entre los muchos textos que conocemos similares para la gestión de unos dominios, resultaría irrelevante de no ser porque en él asistimos al nacimiento de un nuevo concepto. El noble advierte a sus subordinados por si "contra monachos burgenses insurrexerint" de la idea de burgués.

Si bien es cierto, la aparición de este vocablo no nos está hablando de una transformación ya culminada, sino más bien de un proceso largo en el tiempo que empezaba a tomar forma entonces y del que sus contemporáneos aún tardarían en tener conciencia. Asisten ahora al rápido despertar de un nuevo grupo social, que los poderes dominantes de la tradicionalmente feudal Europa -nobleza laica y eclesiástica- ven con el recelo que trasluce la misiva del conde de Anjou. Este grupo social trae consigo el nacimiento y desarrollo de las ciudades y villas medievales desde el siglo XI, lo que la historiografía vino a llamar desde un primer momento el "renacimiento urbano bajomedieval".

No obstante, este revolucionario proceso tardaría en tomar carta de naturaleza hasta al menos el siglo XIII, cuando el nuevo mundo urbano en gestación desde el siglo XI se impusiera definitivamente a la tradicional configuración social medieval. Pero el viejo esquema social tripartito de los tres estados -oratores, bellatores y laboratores- que aún en 1016 y 1036 propugnarían Aldaberón de Laon y Gérard de Cambrai, respectivamente, ya estaba herido de muerte desde 1007.

En este sentido, España no queda al margen de este proceso. De hecho, ya en el texto del fuero otorgado a León por Alfonso V en $1017^{2}$, tan sólo una década después de la carta condal, aparece este fenómeno histórico claramente expresado. Si bien es cierto que en esta época los reinos cristianos de la Península sufren unas peculiares circunstancias propias que la hacen única en Europa, no deja de serlo tampoco el hecho de que hunde con ella sus raíces en el mundo urbano desde el Pleno Medievo.

La historiografía tradicional desde siempre ha venido estudiando el proceso urbano español a la luz del proceso político-militar de la Reconquista y su consiguiente repoblación. Esto obligaba a reducir el fenómeno urbano a las tierras de frontera, las Extremaduras, en constante movimiento por su naturaleza limitánea.

1 PERNOUD, Régine., Histoire de la bourgeoisie en France. I: Des origines aux temps modernes, París 1960, 21-23.

2 PÉREZ DE BUSTAMANTE, Rogelio (coord.), El Fuero de León. Comentarios, León 1983. 
Sin embargo, el fenómeno urbano no se agotará con estas acciones, sino que podemos ver otras muchas actuaciones en los territorios interiores. Al margen de la que se presenta como obligada secuela del avance territorial de los Estados cristianos, se desarrollan otras repoblaciones que nada tienen que ver con el hecho reconquistador. Será una necesidad no sólo ante la recuperación militar de un territorio despoblado, sino también -y a veces mayor- en territorios desde antiguo dominados pero que precisan de una articulación administrativa y social que facilite su gobierno y desarrollo.

Esta promoción, de impulso principalmente regio, se proyectó sobre los territorios que habían quedado marginados de la reactivación de la vida urbana meramente militar, dejándose sentir junto a aquellas regiones beneficiadas por la influencia de las rutas peregrinatorias y contribuyendo decisivamente a impulsar el desenvolvimiento urbano de las áreas norteñas del reino castellano-leonés, modificando sensiblemente sus estructuras político-administrativas, socio-económicas y jurídicas en un proceso de larga duración en el tiempo.

Al hilo de estos planteamientos, con este artículo se pretende analizar el alcance de este proceso en la Galicia de época plenomedieval. Más allá de los tópicos liberales decimonónicos que veían en la Edad Media una época marcada por la eminente ruralidad de una sociedad marcada por el dominio señorial, que se ensañaban de forma especial en el caso de Galicia profundizando más esta imagen, podemos registrar una tradición urbana larga en el tiempo que la coloca en igualdad de condiciones con el resto de las regiones europeas del momento.

\section{LA TRADICIÓN HEREDADA: LA RED URBANA DE LA ANTIGÜEDAD TARDÍA}

Alrededor de 1130 llegó a Santiago de Compostela, destino de su peregrinación, el clérigo poitevino Aymeric Picaud, quien muy probablemente consignara sus experiencias apenas unos años más tarde escribiendo la Guía del peregrino de Santiago (Iter pro peregrinis ad Compostellam) que cierra el conocido codex Calixtinus. En esta obra el francés, a la hora de señalar las características de los lugares que se encuentran a lo largo de la ruta jacobea, describe Galicia como un territorio muy rico pero "escasa en ciudades y villas" 3 . No es extraño que diga esto si lo analizamos desde la perspectiva actual, pues a esta altura de los acontecimientos el

${ }^{3}$ Guía del peregrino medieval (Codex Calixtinus), tr. Por Millán Bravo Lozano, Sahagún 1989, 38. 
fenómeno urbano está dando sus primeros pasos medievales; pero por aquel tiempo se encontraban también en esta posición de salida el resto de regiones que atravesaba el Camino de Santiago tanto en la Península como fuera de ella, y podríamos precisamente hablar de Galicia como una de las regiones más adelantadas gracias al temprano nacimiento de la urbe compostelana.

De hecho, si bien no deja de ser cierto que los territorios del norte peninsular se encontraban entonces sin ningún tipo de articulación urbana siendo una tierra sin ciudades con muy raras excepciones, tampoco puede negarse que todas esas excepciones se acumulan mayoritariamente en territorio galaico. Entre los territorios hispanos, Galicia presenta una singularidad gracias a la continuidad de unas estructuras urbanas premedievales. Galicia se presenta como única región que contaba con una retícula urbana relativamente importante heredada de la Tardoantigüedad y de los reinos germánicos antes de la ruptura que supuso por la invasión musulmana y la reorganización de los primeros reinos cristianos. La tradición urbana en Galicia era bien antigua y con una presencia notable: el Bajo Imperio le proporcionó un tejido urbano a base de la creación de núcleos administrativo-episcopales (Lucus Augusti, Auria, Iria Flavia) y comerciales (Faro, Portus Iuliani, Vigo) cuya actividad continuó sin interrupción hasta su decadencia en las primeras centurias medievales.

Con la implantación en la zona del Reino Suevo la que había sido capital del convento jurídico lucense y capital a efectos prácticos de la Galicia propiamente dicha, Lugo, pierde su papel preeminente. Los suevos implantarán su centro de poder gravitando en torno a las ciudades del sur: Braga, Oporto, Orense y la vieja Tude. Mantendrán vivo, pues, el espíritu urbano de este territorio, que pervivirá incluso tras la conquista visigoda. Cuando se organiza el Reino Suevo, Galicia cuenta con una red urbana conformada por ciudades bien distribuidas, aunque si bien es cierto, físicamente, no pasan de ser pequeñas islas en un océano rural ${ }^{4}$. Nada indica que las ciudades galaico-romanas sufriesen graves destrucciones, ya que los propios suevos se mostraron muy interesados en que la estructura recibida siguiese funcionando. Esta ocupación continuada de la ciudad romana explica la supervivencia del trazado ortogonal en las partes más antiguas de las ciudades, aunque con la novedad de la construcción de residencias regias.

Por otro lado, son bien documentados y resultan de sobra conocidos los contactos marítimos de época sueva y visigoda de Galicia con el mundo franco, aunque éstos no se fundamentarían en ciudades netamente mercantiles sino en pequeños

${ }^{4}$ Hasta el momento, la única incursión en la historia urbana gallega en época sueva es la que hace Anselmo LÓPEZ CARREIRA en A cidade medieval galega, Vigo 1999, 17-36. 
núcleos que actuaban como emporia gracias a su adecuación a un perfil costero que permitía la disposición de puertos naturales en las principales rutas de acceso al interior gallego, en muchas ocasiones sobre asentamientos de pasado romano: la desembocadura del Miño dominada por la ciudad de Tuy, la del río Ulla con los asentamientos de Iria y posteriormente el Portus Apostoli, la actual ría de la Coruña controlada por Faro y Portus Britonniae y en la ribera del Eo el Portus Iuliani, que se prolongaba hacia el interior comunicándose con Lugo. Desde estos modestos asentamientos en la orla costera se produciría incluso una intensificación de los contactos marítimos desde el siglo VI que traería consigo una relativa revitalización urbana, perviviendo cierta autonomía del funcionamiento municipal que tenían hasta entonces.

Sin embargo, desde la siguiente centuria el panorama urbano gallego, como prácticamente el del resto de la Península, vive un período de crisis en lo que han venido a llamarse los "siglos oscuros". Las ciudades se desvanecen paulatinamente, aunque nunca se interrumpe de manera absoluta la vida urbana en ellas. En este momento coincidirán en el tiempo la efímera ocupación musulmana y la reconquista del territorio galaico por el rey asturiano Alfonso I con la dudosa repoblación interior de Fruela entre 759 y $768^{5}$. Son los años de las rebeliones de la nobleza gallega, el tiempo en que se produce la inventio del sepulcro jacobeo con su consecuente despertar del fenómeno peregrinatorio y las continuas incursiones musulmanas en el solar del Reino Asturleonés. Respecto a estas expediciones, la interpretación tradicional cargó de modo desproporcionado el acento sobre los efectos destructivos de las expediciones musulmanas, aunque queda claro que la inestabilidad, la inseguridad de los asentamientos y la inviabilidad del tráfico marítimo por las amenazas de ataques piráticos primero normandos y luego sarracenos tendrían efectos disolventes sobre el mundo urbano. Desde principios del siglo VIII se impone la ruralización y no existen ya propiamente ciudades - de hecho, el término "civitas" se reservó en el lenguaje de la época para designar a los núcleos asiento de sedes episcopales- ${ }^{6}$, sino meros burgos que ya parecen haber perdido un elemento capital de la condición urbana como es la administración municipal.

\footnotetext{
5 “...usque flumine Mineo populata est Gallecia”. GIL FERNÁNDEZ, Juan - MORALEJO, José Luis - RUIZ DE LA PEÑA SOLAR, Juan Ignacio, Crónicas asturianas, Oviedo 1985, 134.

${ }^{6}$ Esto perviviría incluso hasta la época del renacimiento urbano, pues el texto foral concedido a la ciudad de Orense por Alfonso VII en 1131 deja claro que es concedido "ut sit in ea burgus sive civitas" (vid. MARTÍNEZ MARTÍNEZ, Faustino, "Antología de textos forales del Antiguo Reino de Galicia (siglos XII-XIV)", Cuadernos de Historia del Derecho, 10 (2003), 257-343, 309).
} 
De este modo, al situarnos en la Galicia de fines de la Alta Edad Media, a las puertas del fenómeno urbano plenomedieval, nos encontramos un panorama peculiar en el contexto de los territorios cristianos peninsulares que en parte explica lo tardío de la promoción urbana en la zona. En primer lugar, se trata de un área marginal del reino, centrado entonces en la expansión meridional. Esto supondría una estabilidad de la organización del espacio heredada, el lastre de las viejas estructuras, la falta de un enemigo común que facilitara la cohesión y solidaridad interna y la promoción de la sociedad urbana y proporcionase una férrea voluntad de exigencia de libertades que podían tener entonces los espacios de frontera. De hecho, esta marginación impidió incluso que Galicia no se viera muy beneficiada por "la intensa corriente repobladora canalizada por el Camino de Santiago que, desde finales del siglo XI, propiciaría la constitución de un nutrido elenco de burgos nuevos y la reanimación económica de viejos centros de población a lo largo del mismo"7, que sólo se dejaría sentir quizá con menor intensidad y más tardíamente que en los sectores leonés, castellano y navarro de la ruta jacobea ${ }^{8}$.

Por otra parte, en el noroeste peninsular la presencia de poderosos señoríos eclesiásticos, catedralicios y monásticos así como de la nobleza laica resultaba enorme. Esto se traducía en el ejercicio de una presión social y económica que se presentó como un obstáculo a las políticas de promoción urbana, que supondría la introducción de nuevos factores de desequilibrio en los intereses señoriales. Ejemplo de ello son las hostilidades manifiestas de las sedes episcopales gallegas -y también la ovetense- y los grandes monasterios ante los aforamientos regios de nuevos villazgos a partir del siglo XI y las subsiguientes situaciones de conflicto9.

Asimismo, la orla costera cantábrica en época altomedieval presenta una lamentable situación, sometida a las incursiones piráticas de normandos y musulmanes que se prolongarían hasta época gelmiriana. Esta situación imposibilitará la consolidación de formas superiores de poblamiento del litoral gallego, provocando un

7 RUIZ DE LA PEÑA SOLAR, Juan Ignacio, "El desarrollo urbano de la periferia norteña castellano-leonesa en la Edad Media (siglos XII-XIV)”, Anuario de Estudios Medievales, 19 (1989), 169$186,171$.

8 Sobre la repoblación urbana y las colonizaciones francas en el Camino de Santiago vid. ídem "Repoblación y sociedades urbanas en el Camino de Santiago", El Camino de Santiago y la articulación del espacio hispánico. XX Semana de Estudios Medievales de Estella, 1993, Pamplona 1994, 271-314.

9 Ídem. "Los procesos tardíos de repoblación urbana en las tierras del norte del Duero (siglos XIIXIV)", Boletín del Instituto de Estudios Asturianos, 88 (1976), 735-77, 745-46; y más recientemente "Desarrollo urbano y reacción señorial: monasterio 'versus' concejos en el noroeste peninsular (siglos XII-XIII)”, El monacato en los reinos de León y-Castilla (siglos VII-XIII). X Congreso de estudios medievales de la Fundación Sánchez Albornoz, 2005, León 2007, 327-60. 
gran retraso en los conocimientos y técnicas navales de los gallegos ante su subdesarrollado tráfico comercial y pesquero. La pacificación de la costa, las actuaciones de Gelmírez con la importación de marinos genoveses y pisanos y la creciente afluencia de peregrinos por vía marítima permitirán una primera salida en falso al mundo marítimo por parte de Galicia, aunque aún en la época inmediatamente anterior a la promoción urbana plenomedieval presentará una red portuaria apenas articulada $^{10}$.

Otro factor a tener en cuenta es que, pese a la eminente ruralidad de las formas de vida, Galicia es un territorio densamente poblado. Ello supone una teórica facilidad para encontrar pobladores para las nuevas fundaciones sin depender de las aportaciones del exterior -especialmente del elemento franco- ${ }^{11}$, aunque en ocasiones éstos deban librarse de la dependencia señorial, produciéndose tensiones.

Finalmente, no se puede olvidar la principal característica única del territorio gallego medieval, la existencia de unos firmes antecedentes urbanos que permanecen latentes, bien a través de las cinco civitates episcopales que ofrecen en esta época una estructura urbana medianamente consolidada -especialmente Santiago, favorecida por las peregrinaciones al sepulcro del Apóstol, Lugo y Orense, y en menor medida Tuy y Mondoñedo- o de unas realidades preurbanas que constituirán el germen de las futuras fundaciones. Son, en cualquier caso, núcleos de larga tradición que empiezan a actuar como centros de organización del territorio y que mantienen activa una red viaria que constituirá a su vez un importante factor en el proceso de promoción urbano que se producirá en las siguientes centurias.

\section{LOS PROCESOS PLENOMEDIEVALES DE REPOBLACIÓN URBANA}

Europa entera constituye desde finales del siglo X un mundo en expansión con las primeras apariciones de las realidades urbanas ya consideradas como tal, y Galicia no queda atrás en el proceso. La ciudad medieval es plenamente comprensible en el contexto de la sociedad feudal, siendo al mismo tiempo producto de su desarrollo y origen de su amortización. El camino emprendido se vuelve pronto irreversible.

10 FERREIRA PRIEGUE, Elisa, "El comercio de las villas costeras de Galicia en la Baja Edad Media", Museo de Pontevedra, 43 (1990), 247-264.

11 Entendiendo franco en el sentido medieval de los francigeni, es decir, designando con ello no sólo a los procedentes del Reino Franco, sino en general a todo aquel forastero de más allá de los Pirineos. 
Los orígenes de la promoción urbana en Galicia se han explicado a lo largo de la historiografía poniendo el acento bien en su naturaleza como fruto de un desarrollo económico-comercial y la atracción de la inmigración rural al foco urbano ${ }^{12}$, o bien en la interesada actuación regia para hacer presente su autoridad en una Galicia dominada por los intereses señoriales ${ }^{13}$ aún sin una consolidada organización del espacio ${ }^{14}$. Sin duda todos estos factores son ciertos y, en conjunto, debieron conformar la coyuntura que permitió el desenvolvimiento del proceso urbanizador gallego.

Desde finales del siglo $\mathrm{X}$ se registra en las realidades preurbanas -tanto burgos como civitates- un aumento de su importancia y su presencia, comenzado a asumir tímidamente el papel de reordenadotes y directores de sus correspondientes territorios. Sin embargo, no es posible considerar a los núcleos gallegos como ciudades antes del siglo XII, aunque Compostela quizá sí con anterioridad. Es cierto que las sedes y burgos comienzan a organizarse espacial y socialmente, con un tenue crecimiento geográfico, y a asumir las funciones señaladas, pero habrá que esperar, no obstante, hasta la duodécima centuria para ver asentada la ciudad medieval propiamente dicha, con una madurez institucional propia.

Se trata de un largo proceso acumulativo en el que resulta inútil pretender fijar un momento absoluto a partir del cual podamos hablar propiamente de una ciudad; pero parece acertado escoger como punto de partida la existencia de un cuerpo jurídico que regule la vida urbana desde los aspectos básicos como el emplazamiento hasta la compleja estructura institucional y las dependencias de los poderes exteriores. Esta tipificación jurídico-formal se produce en el momento de la concesión a la nueva villa de una carta puebla, un texto de sanción regia que concede a los nuevos pobladores un estatuto jurídico privilegiado constituyendo el "acta fundacional o de nacimiento" de la nueva realidad urbana. Se trata de documentos de carácter público emanados del poder real -y subsidiariamente del poder episcopal o señorial-, cuya conceptuación como una categoría especial dentro de los ordenamientos locales deriva de su orientación finalista repobladora en cuanto constituyen la expresión jurídica de una concreta voluntad fundacional ${ }^{15}$. Un punto aparte,

12 A cidade medieval galega, 63-70

13 GARCÍA ORO, José, Galicia en los siglos XIV y XV, 2, Pontevedra 1987, 9-18.

14 FERREIRA PRIEGUE, Elisa, "El poblamiento urbano en la Galicia medieval", El fenómeno urbano medieval entre el Cantábrico y el Duero. Revisión historiográfica y propuestas de estudio, Santander 2002, 367-420.

15 Cf. GARCÍA GALlO, Alfonso, "Aportaciones al estudio de los fueros", Anuario de Historia del Derecho Español, 26 (1956), 387-446; y también FONT RÍUS, José María, Cartas de población y franquicia de Cataluña, 1, Madrid 1983, 10-15. 
pues, en este conjunto de textos jurídicos es la figura de los contratos agrarios colectivos, de carácter predominantemente privado y que se vienen conociendo como fueros agrarios, que sirvieran para la ordenación de poblaciones menores y resultan tan abundantes en Galicia ${ }^{16}$.

Atendiendo a la procedencia de estas cartas forales, apreciamos una gama enormemente rica si atendemos a la reducida extensión del territorio en que se conceden. En un primer momento, el modelo a seguir parece ser el del Fuero de León, en que se fundamenta el fuero concedido a Compostela y algunas de sus villas dependientes como Noya, así como a la ciudad de Mondoñedo. También será de capital importancia la entrada del Fuero de Sahagún, en especial gracias a la versión que se aplicará a la villa de Allariz (1152) y se extenderá posteriormente a otras poblaciones como Orense, Ribadavia o Bonoburgo de Caldelas. Sin embargo, el más extendido será sin duda el Fuero de Benavente, que será el concedido a las fundaciones de Alfonso XI y muchas de las sucesivas: Milmanda, La Coruña, Burgo del Valle de Oro, Parga, Betanzos, Ortigueira, Puentedeume, Muros... Y, por último, no hay que olvidar la serie de fueros propios, sin conexión alguna con las grandes familias forales de procedencia leonesa que se fundamentan en una amalgama de sucesivos privilegios que dan como fruto un texto foral elaborados específicamente para ellos que se ven en fundaciones como Tuy, Padrón, Pontevedra, Lobera y Caldas de Reyes. Otros muchos, incluso de importantes villas como Ribadeo o Vivero, no han llegado a nuestros días, desconociéndose por tanto su origen.

Esta concesión de un estatuto privilegiado corría generalmente a cargo, como se ha podido intuir, de los monarcas, verdaderos artífices del proceso urbanizador en el norte peninsular. En la mayoría de los casos, a pesar de la presencia de poderes señoriales y los posibles hechos consumados, la fundación de la ciudad o villa como persona jurídica se refrenda mediante un acto administrativo privilegio exclusivo del rey. No obstante, en el territorio gallego contamos con la constante presencia de fuertes poderes señoriales cuasi soberanos, especialmente el de los arzobispos compostelanos en su señorío, que llevarán a cabo en época ya bajomedieval iniciativas urbanizadoras propias, aunque de carácter mucho menor, como en el caso de las pesquerías de las Rías Bajas.

16 Lamentablemente aún no existe un estudio global del tema para Galicia como para otras regiones españolas (RUIZ DE LA PEÑA SOLAR, Juan Ignacio, "Fueros agrarios asturianos del siglo XIII", Asturiensia Medievalia, 4 (1981), 131-96), aunque hay aportaciones muy loables como las referentes al grupo foral del monasterio de Meira: SÁEZ SÁNCHEZ, Emilio., "Cartas de población del monasterio de Meira", Anuario de Historia del Derecho Español, 26 (1956), 500-19; y "Antología de textos forales de Galicia”, 294-300. 
Asimismo, estos poderes, tanto laicos como eclesiásticos, protagonizarán una constante tendencia a la señorialización de las urbes gallegas. En los primeros momentos, muchos de los proyectos regios acabarán frustrados por su presión y terminarán en manos de la clase episcopal como un dominio más de su señorío. Tampoco será extraño la entrega de las villas realengas a poderosos nobles cortesanos como tenentes que aspiran a hacer de ellas coto solariego de su señorío. Además, ya en las últimas centurias del Medievo, especialmente con el asiento de los primeros Trastámara, muchas serán entregadas a señores privativos. Incluso las escasas poblaciones que se libren de ello y permanezcan en el realengo sufrirán las continuas actuaciones y presiones de la poderosa nobleza galaica, que se introducirá en sus órganos de gobierno concejiles buscando patrimonializarlos y beneficiarse de ellos.

Se pretende ahora exponer una síntesis del proceso repoblador atendiendo en la medida de lo posible la totalidad de los núcleos urbanos gallegos de origen medieval, pero desde una perspectiva diacrónica. A ese respecto se puede observar una serie de campañas u operaciones que se suceden en el tiempo y van conformando el mosaico urbano que heredará la Galicia moderna. Se aprecia una primera etapa de inicios repobladores que se concentrará en las ciudades episcopales principalmente, y que coincide con los reinados de Alfonso VI (1072-1109) -junto a la figura de Raimundo de Borgoña como conde de Galicia (1095-1107)- y de Alfonso VII "el Emperador" (1126-1157)17. A continuación, con la separación de los Reinos de León y Castilla, la actividad de los monarcas leoneses en la urbanización de Galicia proporciona los principales frutos del proceso tras unos primeros ensayos que acaban frustrándose con Fernando II (1157-1188) y la definitiva actuación repobladora regia que se da con Alfonso IX (1188-1230). Finalmente, los remates en tierra galaica por las fundaciones de Fernando III (1230-1252), Alfonso X (12521284) y Sancho IV (1284-1295).

La actuación regia, aunque siendo coincidentes en el tiempo y hasta en ocasiones en un mismo emplazamiento, suele responder a los siguientes objetivos ${ }^{18}$ :

- Organización de la población laica, dedicada mayoritariamente a actividades mercantiles, que se ha ido asentando en torno a las viejas sedes episcopales.

- Consolidación de la línea fronteriza con el Reino de Portugal.

- Establecimiento de villas portuarias para la explotación de los recursos del litoral gallego y abrir la región al tráfico comercial extranjero.

17 Se obvia aquí el reinado de doña Urraca (1109-1126) debido a que no se registra actividad repobladora urbana en Galicia entonces.

18 Vid. "El poblamiento urbano en la Galicia medieval", 370. 
- Creación de etapas el las rutas peregrinatorias a Santiago de Compostela, sobresaliendo el Camino Francés.

- Proporcionar un centro urbano que articule los territorios de realengo, especialmente en las tierras interiores.

Esta variedad de intenciones, unido a la diversidad de los condicionamientos locales en tan dilatado espacio en que actúa la acción repobladora y su prolongado escalonamiento a lo largo de dos centurias generarán, obviamente, ciertas variantes y modalidades particulares en el desenvolvimiento del fenómeno urbano, aunque se observen en todas sus manifestaciones unos paralelismos de base, tanto en sus motivaciones como en sus mecanismos de ejecución y en sus consecuencias, que justifican su tratamiento global como expresión de un proceso histórico de estructura unitaria, aunque sea en un ámbito regional como es el gallego, y del que se hablará a continuación.

\subsection{Primera etapa: Tímidos comienzos de la política de promoción urbana con} Alfonso VI y Alfonso VII (1085-1157)

En este primer momento, los reyes parecen inclinarse esencialmente por actuar sobre los núcleos de población que en torno a las viejas sedes episcopales han ido constituyendo comunidades vecinales a la manera de burgos. Tres de las cinco civitates episcopales gallegas poseen una larga tradición urbana que hunde sus raíces en época romana, sueva y visigoda -nos referimos a Lugo, Orense y Tuy-, pero desde entonces atravesarán los "tiempos oscuros" en un período de despoblaciones y repoblaciones no muy bien documentadas hasta que, definitivamente asentadas, desarrollarán nuevos burgos junto al núcleo primitivo. La desolación, despoblación cierta, de las ciudades episcopales será palpable en una sociedad prácticamente ruralizada, hasta el punto de ser puntos inseguros para la vida hasta de los propios prelados $^{19}$. Sin embargo, estos núcleos siguen siendo puntos de referencia en la geografía y la mentalidad de los hombres de la época, volviendo a ella desde el siglo XI la autoridad eclesiástica y la civil, y un cúmulo de nuevos grupos de primeros burgueses que serán los protagonistas de esta promoción.

La primera actuación que se registra parece ser en la ciudad de Lugo. Este núcleo, antigua capital romana de la Galicia propiamente dicha siendo seguramente una ciudad de gran importancia ${ }^{20}$, había sufrido la despoblación y la conquista

19 "El poblamiento urbano en la Galicia medieval", 370-72.

20 Así lo denuncia al menos la imponente monumentalidad de su muralla, que encierra un recinto urbano de $30 \mathrm{Ha}$. 
musulmana hasta la reconquista por Alfonso I y la subsiguientes presuras llevada a cabo por Odoario, según nos deja ver el sospechoso corpus odoariano del Tumbo Viejo de Lugo, así como las sucesivas invasiones normandas y los compromisos de defensa por los infanzones y magnates gallegos, igualmente dudoso ${ }^{21}$. En cualquier caso, ciertos o no, los relatos resultan verosímiles y nos hablan de la paulatina recuperación de la ciudad: la riqueza de una urbe episcopal objeto de saqueos, la reorganización eclesiástica por parte del obispo, su papel de nuevo como centro rector y nudo viario del territorio oriental y su situación en la vía de comunicación con las cortes del Reino Asturleonés y en la ruta peregrinatoria a Santiago desde el Oviedo de las reliquias contribuyó a que entre finales del siglo XI y las primeras décadas del siguiente la afluencia de población acabase conformando el burgo con una importante colonia franca ${ }^{22}$. Precisamente de ese tiempo data la primera noticia de una estimulación de la población por parte de Alfonso VI, quien concede a la ciudad de Lugo un primer estatuto jurídico en torno a los años 1088 y 1090, texto que hoy desgraciadamente se ha perdido ${ }^{23}$. A lo largo de la primera mitad del siglo XII, Lugo será escenario de violentos acontecimientos fruto de la crisis sucesoria ${ }^{24}$ a la par que la comunidad de vecinos, seguramente aún no institucionalizada en un concejo o municipio, experimenta sus primeros conflictos con el obispo que tenemos documentados desde 1158, hasta el punto de obligar al entonces monarca, Fernando II, a tomar cartas en el asunto.

Sin embargo, la primera ciudad propiamente medieval en Galicia será Santiago de Compostela, la civitas Sancti Iacobi. La inventio del sepulcro del Apóstol en territorios del obispado de Iria Flavia, una sede episcopal menor constituida en la tardorromanidad -a finales del siglo VI-, convertiría al enclave urbano que se constituiría a su alrededor en el corazón de la cristiandad hispánica, a nivel europeo comparable con Roma o Jerusalén con un poder de atracción peregrinatorio inconmensurable. Poco conocemos de sus comienzos, en los que tendría un importante papel el elemento franco, pero también la población rural del país y de otros elementos urbanos que constituirían a partir del siglo IX uno de los escasos casos de ciudades ex novo en un proceso espontáneo, ya que en Compostela no hay civitas previa ni previsión sobre ello ${ }^{25}$. Entre 950 y 1050 tiene lugar su gestación urbana

21 Acerca de la Alta Edad Media de Lugo, vid. ABEL VILELA, Adolfo de, La ciudad de Lugo en los siglos XII a XV, Santiago 2009, 55-63.

22 Ibíd. 72-78.

23 "Antología de textos forales de Galicia", 290.

${ }^{24}$ La ciudad de Lugo, 67-68.

25 LÓPEZ ALSINA, Fernando, La ciudad de Santiago de Compostela en la Alta Edad Media, Santiago de Compostela 1988, 243-266. 
con un recinto amurallado edificado, pero que desde 1050 envolverá por una nueva muralla única el suburbium que desde su nacimiento se había formado extramuros, confiriendo a la ciudad una estructura dual clásica ${ }^{26}$ : "prius villa burgensis, deinceps municipium fuit" 27 . Desde principios del siglo X parecen gozar de privilegios reales de importancia económica, que permiten la frecuencia del "hospedaje" a mercaderes extranjeros atraídos por el negocio peregrinatorio ${ }^{28}$, que permite la recuperación de la ciudad incluso tras la destrucción por Almanzor en 997. A lo largo del siglo XI se constituye un vecindario burgués con componentes francos y lombardos en un inicio, pero que desde la siguiente centuria es mayoritaria o totalmente gallego. Su aforamiento parece ser muy antiguo, pues los compostelanos dicen acogerse al Fuero de León de 1017, concedido por Alfonso V en 1019 pero que no se conserva y se menciona en diplomas posteriores ${ }^{29}$, época en que debe formarse el municipio ${ }^{30}$. Sin embargo, con esta ciudad ya plenamente constituida en un crecimiento auspiciado por las peregrinaciones, en 1095 se produce una primera concesión por Raimundo de Borgoña, y apenas diez años más tarde, concede un nuevo texto foral confirmado por Alfonso VI, del que se han conservado solamente unos fragmentos. Se trata de un conjunto privilegiado de exenciones, libertades y franquezas junto a otros fueros y costumbres que venían ya gozando los compostelanos orientados a la protección del comercio y de las peregrinaciones ${ }^{31}$. También en 1095, ante la importancia que ha cobrado la sede compostelana, se extingue la antigua y cercana cátedra iriense, que pierde con ello sus posibilidades de promoción urbana, quedando condenada a ser prácticamente un arrabal de la villa de Padrón.

La siguiente concesión foral será sobre la antigua Auria, ciudad de pasado romano que gozará de sede episcopal desde época sueva. Sin embargo, su historia altomedieval nos resulta aún muy mal conocida, y las pocas noticias que conservamos nos hablan de una precaria existencia de un núcleo despoblado y desolado en torno a la sede episcopal que sufre los tiempos difíciles de las invasiones musulmanas e

26 Íbid. 248-249

27 Privilegio de Pascual II de 1105 (Íbid. 145, n. 5).

28 FERREIRA PRIEGUE, Elisa, "De Ciudad Santa a plaza mercantil. Los fundamentos de la función económica de Santiago en la Edad Media”, Santiago de Compostela: ciudad y peregrino. Actas del V Congreso Internacional de Estudios Jacobeos, Santiago 2000, 351-83, 374-75.

29 En 1253 declaran regirse "por fuero de León, e por costunbres derechas e por razones guisadas e por el Libro Judgo" (LÓPEZ FERREIRO, Antonio, Fueros municipales de Santiago y su tierra, Santiago 1895, 211).

30 La ciudad de Santiago de Compostela, 270.

31 "Antología de textos forales de Galicia", 286-87. 
incursiones normandas bajo mínimos hasta, al menos, la restauración de Sancho II en $1071^{32}$. Es muy probable que en torno a ese momento se empiece a formar el burgo artesanal en torno a la reorganizada sede, con un primer privilegio de concesión de un mercado por doña Teresa de Portugal en $1122^{33}$ y las costumbres otorgadas por el obispo don Diego Velasco para fomentar la repoblación a petición de un grupo escogido de vecinos y con el beneplácito de la reina doña Urraca entre 1112 y 1126, que constituirán el núcleo primitivo de los fueros orensanos. Unos años después, en 1131, habrá una nueva concesión por parte de Alfonso VII por el que se extiende a la ciudad de Orense el Fuero de Allariz ${ }^{34}$, con expresivas referencias a su floreciente pasado que se intenta recuperar con una industria vitivinícola de prometedor futuro.

Otra atención a una civitas episcopal en este período será la concesión a la localidad hoy pontevedresa de Tuy de un primer fuero breve de manos del Emperador en $1142^{35}$. Sin embargo, dada la historia de este núcleo, se abordará más extensamente más adelante.

Por último, la quinta y más modesta de las civitas episcopales gallegas es, tal vez, la que posee una historia más azarosa y compleja fruto de su unión a los destinos de la sede. Nos referimos a Mondoñedo, debiendo diferenciar entre la sede episcopal de Mondoñedo o Mindonietum y la ciudad de Mondoñedo. La primera es una sede altomedieval en teoría heredera de la sede Laniobrense de Britonia y la de Dumio $^{36}$, con una difusa sede urbana que se ubicaba en un lugar de la costa norte denominado Mindonietum con anterioridad al siglo X. Desde allí se desplazaría al valle de Brea, creciendo a su alrededor un pequeño burgo que tomará el nombre de Villamayor, una antigua villa rural a la que se acota un alfoz. Este traslado en torno a 1117 pudo estar relacionado con un deseo de ubicar la cátedra en una posición en el camino desde Asturias en dirección a Santiago sobre la ría del Eo, pudiendo con ello combinar el papel religioso con el mercantil. En cualquier caso, sobre este núcleo preurbano nacerá la ciudad de Mondoñedo como fruto de una decisión de Alfonso VII en el año $1156^{37}$, promocionando el núcleo -rebautizado ya como

32 DURANY CASTRILlO, Mercedes, "Ourense na Idade Media", Historia de Ourense, La Coruña 1996, 119-75, 119-23.

33 Íbid. 125.

34 "Antología de textos forales de Galicia", 308-09

35 Íbid. 332-33.

36 MAYÁN FERNÁNDEZ, Francisco, Historia de Mondoñedo. Desde sus orígenes hasta 1833, en que dejó de ser capital de provincia, Lugo, 1994, 21-22.

37 El documento fundacional de la ciudad por Alfonso VII en FLÓREZ, Enrique, España sagrada, 23, 348 . 
Villamayor de Mondoñedo- a la categoría de ciudad concediéndole el Fuero de León, confirmando su alfoz y dotándolo de funciones comerciales gracias a un privilegio de mercado mensual y feria anual de ocho días por la Virgen de agosto, entregándosela finalmente al señorío episcopal ${ }^{38}$. Sin embargo, la sede sufrirá en 1182 un nuevo traslado a la recién constituida villa de Ribadeo, aunque con un carácter pasajero, pues Villamayor seguirá ostentando un rango urbano y será administrada en la distancia por la mesa episcopal. Habrá que esperar hasta 1233 para ver de nuevo la sede en Villamayor, ya con carácter definitivo, y ya con el nombre de Mondoñedo. Pero si bien tendrá un rango superior debido a su naturaleza episcopal, no pasará de ser realmente una villa de segundo orden con una pujanza económica sin desarrollar pese a su relación con las pujantes villas costera del norte de la diócesis y que orbitará económicamente en torno a Lugo.

En esta primera etapa de tímidas actuaciones urbanas de los reyes, entre semejantes acciones sobre las civitates episcopales tienen cabida tan sólo dos nuevos núcleos urbanos. El primero de ellos, de gran importancia en la historia medieval gallega, es la villa de Allariz. Se trata ésta de una fundación a medio camino entre la consolidación y fortificación de la línea fronteriza con Portugal por su situación en las cercanías y la ordenación de los territorios de realengo gallegos. Responde, bajo este último aspecto, a la necesidad regia de hacerse presente en los territorios de su dominio que se encuentran o bien descentralizados o bien bajo la jurisdicción de un tenente o merino que con frecuencia ejerce de facto un cuasi señorío propio. En este caso, se trata de una de las ciudades de primer rango del interior gallego, llamada a ser la capital de la región de la Limia, siendo el mejor y más antiguo ejemplo de este grupo. Es en origen un castillo realengo sobre un viejo castro en la ribera del río Arnoia, seguramente creado por Alfonso VI como plaza fuerte de los tenentes de la Limia, que sería donada a doña Urraca en $1112^{39}$. Con anterioridad a 1130 se le concede un primer fuero, cuyo contenido se desconoce, y en 1145 parece ya una ciudad plenamente constituida a juzgar por la donación que Alfonso VII hace entonces de parte de sus rentas al obispo de Orense ${ }^{40}$. Sin embargo, la más importante actuación del Emperador en Allariz será la concesión en agradecimiento por la fidelidad mostrada frente a la independencia portuguesa en 1152 de un

38 LÓPEZ ALSINA, Fernando, Introducción al fenómeno urbano medieval gallego a través de tres ejemplos: Mondoñedo, Vivero y Ribadeo, Santiago de Compostela, 1976, 36-38.

39 ANTONIO RUBIO, Ma Gloria de - GONZÁLEZ PAZ, Carlos A., "Allariz: aspectos urbanos de una ciudad gallega con judería en el siglo XIII", El mundo urbano en la Castilla del siglo XIII, 2, Sevilla, 2005, 42-52.

40 "El poblamiento urbano en la Galicia medieval", 384. 
nuevo fuero derivado del de Sahagún, al que remite como derecho supletorio y con el que comparte más de dos terceras partes de su contenido ${ }^{41}$, con un carácter mucho más militar, pero llamado a extenderse por numerosas villas gallegas.

Respecto a la otra actuación mencionada, se trata de la villa de Ferrol, que por una confirmación tardía de sus fueros hace atribuirle también a Alfonso VII su poblamiento inicial, aunque desconocemos en que fecha y condiciones ${ }^{42}$. Pudo tratarse de un primer ensayo del aprovechamiento de los ricos recursos de la costa gallega para su explotación económica y el servicio a los peregrinos por vía marítima. Sin embargo, no podemos olvidar que en ese momento la costa gallega aún presenta un perfil portuario completamente desarticulado y los conocimientos navieros gallegos aún están en una fase embrionaria, de forma que habrá que esperar hasta la siguiente fase para asistir a la promoción urbana de la costa galaica.

\subsection{Segunda etapa: El período álgido de la promoción urbana regia durante la división de reinos (1157-1230)}

En esta segunda fase del fenómeno urbano Galicia se convertirá en la zona más beneficiada por la actividad fundacional de nuevos centros de toda la periferia norteña peninsular, y primero y más intensamente en las tierras de su fachada litoral. La seguridad de los mares, recobrada tras el fin de las incursiones piráticas en esta costa, lo progresos en las artes náuticas gracias a los servicios de expertos italianos contratados por el arzobispo Gelmírez, el deseo de facilitar la peregrinación por vía marítima a Compostela y, especialmente, las lucrativas posibilidades económicas que ofrecía la constitución de nuevos centros impulsores de la explotación de la riqueza pesquera y del tráfico comercial marítimo explican esta atención urbana preferente de los monarcas por la promoción costera.

Es así como en la dilatada fachada litoral gallega, desde el Eo hasta el Miño, surgirán ahora un gran número de nuevos villazgos, aunque prácticamente en todas las ocasiones sobre pequeños establecimientos portuarios preexistentes que se remontan incluso a época romana -como en el caso de La Coruña, Ribadeo, Padrón e

41 ARIAS SANTIAGO, A., "Fundación de la villa de Allariz: el fuero otorgado por Alfonso VII", VII Xornadas de Historia de Galicia, Orense 1995, 13-36; y "Antología de textos forales de Galicia", 276-78.

${ }^{42}$ El infante don Sancho confirma en 1283 al concejo de Ferrol todos sus fueros y costumbres que tuvieron de los reyes anteriores "e del Emperador que fueron ante en España" ("El desarrollo urbano de la periferia norteña castellano-leonesa", 170). 
incluso Tuy- cuyo emplazamiento primitivo en muchas ocasiones se traslada a un nuevo lugar por decisión regia ${ }^{43}$.

En un primer momento destaca la repoblación costera de Fernando II, quien emprenderá la fundación de nuevas villas portuarias que, sistemáticamente, pasarán a la dependencia del señorío eclesiástico. El primero de ellos, de nuevo relacionado con la tradición jacobea y uno de los principales entrantes para llegar a la ciudad por mar desde tiempos remotos, es el asentamiento de Padrón en el saco de la ría de Arosa. Se trata de un emplazamiento donde a buen seguro hubo un estrato preurbano, debido a la idoneidad para el asentamiento de un puerto y su naturaleza como tradicional puerto de acceso al interior gallego ${ }^{44}$. Padrón además asumiría el papel ordenador del territorio tras la decadencia de la Iglesia de Iria Flavia en beneficio de la sede compostelana. Los primeros síntomas de transformación de Padrón como burgo se documentan desde 1050 relacionados con la peregrinación franca a Compostela, aunque los mayores cambios serán con el obispado de Gelmírez ${ }^{45}$. Recibirá este núcleo aforamiento por parte de Fernando II en febrero de 1164, confirmando los usos y prácticas desarrollados en la villa desde antaño, junto con ciertos privilegios y franquezas dirigidos a sus vecinos, pero confirmando también el señorío episcopal sobre la villa ${ }^{46}$ de una manera aún más favorable para la sede que en la propia ciudad compostelana ${ }^{47}$.

Un camino similar recorre Noya. En abril de 1168 el mismo monarca fundaba y concedía el fuero de Compostela a la parroquia de Santa Cristina de Noya, en la desembocadura del Tambre y sobre la ría que lleva su nombre ${ }^{48}$. Lo hace en connivencia con el arzobispo por la necesidad de un centro rector que aglutinase los pequeños núcleos ya existentes en la ría, que ofrecía unas posibilidades aún mejores para el tráfico marítimo, concediéndole también su dominio. Junto con Padrón, Noya aseguraba la llegada por mar de peregrinos a Santiago ya que en el fuero concedido Fernando II señala que lo hace "ad restaurationem portus Apostoli". No obs-

43 LÓPEZ ALSINA, Fernando, "'Pro utilitare regni mei': as cidades e a orla costeira do Miño ao Deva no reinado de Alfonso IX de León”, Alfonso IX y su época: pro utilitate regni mei, La Coruña 2008, 187-223.

44 "El poblamiento urbano en la Galicia medieval", 394-95.

45 LOPEZ ALSINA, Fernando, "La formación de los núcleos urbanos de la fachada atlántica del señorío de la Iglesia de Santiago de Compostela en el siglo XII: Padrón, Noya y Pontevedra", Jubilatio. Homenaje de la Facultad de Geografía e Historia a los profesores don Manuel Lucas Álvarez y don Ángel Rodríguez González, 1, 107-17.

46 "Antología de textos forales de Galicia", 310-11.

47 Galicia en los siglos XIV y XV, 153-154.

48 "Antología de textos forales de Galicia", 303-04. 
tante, ya en el siglo XIII, Noya recibirá por el arzobispo Juan Arias una extensión del fuero de Pontevedra, con algunas correcciones y añadidos ${ }^{49}$.

Sin embargo, el gran puerto de la Tierra de Santiago nacerá como intento de villa realenga de marcada vocación marinera desde un primer momento sobre una pequeña aglomeración que controlaba el paso de la ría del Lérez mediante un viejo puente de origen romano en la vía entre Braga y Santiago colonizado por monasterios benedictinos. En 1169 Fernando II concede un estatuto sumamente privilegiado a este núcleo, con el fin de estabilizar a la población de esta feligresía de Santa María y atraer nuevas gentes y promover su explotación comercial y pesquera ${ }^{50}$ que conocemos por posteriores confirmaciones ${ }^{51}$. Supone el nacimiento de la villa de Pontevedra, para lo que debe compensar a los monasterios de Poio y Armenteira, acabando por donarlo íntegramente a la sede compostelana en 1180. Pontevedra está llamada a ser una de las principales fuentes de ingresos de la Mitra santiaguesa y convertirse en la primera potencia pesquera gallega, protagonizando un consecuente desarrollo sorprendente con entidad urbana ya desde comienzos del siglo XIII y un modelo claro de burgo amurallado (el llamado Burgo Pequeno) en torno al que surgen arrabales pesqueros (Moureira) que acaban integrándose en la vida urbana $^{52}$.

De hecho, incluso la promoción que buscará Fernando II con su actuación sobre la ciudad episcopal de Tuy busca en cierto modo la creación de una villa portuaria en el estuario del Miño, función que Tuy ostentará. Tuy se alza encaramada en una colina sobre el Miño donde antes hubiera un castro de ocupación romana, sueva y visigoda que, seguramente en época tardorromana, vería la fundación de la sede tudense. Tras las vicisitudes de conquista musulmana y reconquista desde Asturias similares al resto de civitates, en 1095 Raimundo de Borgoña le concede un coto y la dispone bajo la autoridad del obispo; lo que confirma el aforamiento del Emperador de 1142 antes señalado. A sus pies, en la parte llana junto a la orilla del río, se irá formando desde entonces el burgo de Bonaventura. En estas circunstancias Fernando II en 1170 concedió al burgo unos fueros que anulan el anterior, y por diferentes razones obliga a su traslado a lo alto, a la ciudadela episcopal fortificada, perdiendo su nombre y llamándose Tuy ${ }^{53}$. La reacción debió ser una gran pro-

49 Íbid. 304-07.

50 ARMAS CASTRO, José, Pontevedra en los siglos XII a XV. Configuración y desarrollo de una villa marinera en la Galicia medieval, Pontevedra 1992, 52-55.

51 Se trata de una confirmación de Alfonso X "el Sabio" ("Antología de textos forales de Galicia", 321-322).

52 Pontevedra en los siglos XII a XV, 115-118.

53 "Antología de textos forales de Galicia", 333-35. 
testa, pues apenas más tarde, en abril, anula el documento anterior ${ }^{54}$, aunque éste volverá a entrar en vigor en una fecha desconocida ${ }^{55}$. Así, el resultado será el traslado de los pobladores de la villa a lo alto y la disposición bajo el señorío del obispo, que impone la fusión urbana ${ }^{56}$.

Como último enclave portuario de Fernando II, en la costa septentrional de Galicia la primera fundación se produjo hacia 1182, cuando concedió el fuero -hoy desconocido- 57 a Ribadeo, situado estratégicamente en la ribera izquierda de la desembocadura del Eo, enclave adecuado para una actividad económica principalmente basada en el comercio y la explotación de los recursos del mar, pero también en un importante cruce de caminos. Se funda sobre el romano Portus Iuliani, en un emplazamiento idóneo donde Fernando II lleva a cabo un simple proceso de repoblación expropiando primeramente el lugar elegido y concediendo la carta puebla. Para evitar el fracaso del asentamiento por disensiones con los poderes señoriales de la zona decide otorgar su administración al más fuerte de ellos, la sede mindoniense, que el monarca traslada a su nueva fundación ${ }^{58}$. Progresivamente, la nueva villa se muestra floreciente, y poco a poco parece ir dando mayores muestras de independencia respecto del poder señorial hasta conseguirla totalmente ${ }^{59}$.

Por último, durante el reinado de Fernando se dejaría sentir también en las zonas interiores de Galicia la actividad fundacional regia de nuevos villazgos en territorios tradicionales de realengo, siguiendo el modelo de Allariz. El primero de ellos es la villa de Ribadavia, fundado como centro del territorio de Castella de Bubal, una rica y antigua comarca vitivinícola en un excepcional nudo de comunicaciones. Posiblemente desde la década de 1060 se va conformando un burgo de "Ripa Avie" en torno al castillo del tenente, al que es posible que el emperador de concediese una primera carta puebla en $1130^{60}$. Sin embargo el aforamiento definitivo se producirá con Fernando II en febrero de 1164 a petición de una comisión de los bur-

54 Íbid. 335.

55 "Aunque momentáneamente, como prueban los documentos, fueran anulados por el rey pocos días después de ser por él otorgados, la forma en que quedó terminada la lucha entre el obispo don Lucas y el concejo en tiempos de Fernando III prueba haber mantenido en vigor dichos fueros, aunque se ignore cuando pudieran ser rehabilitados" (GALINDO ROMEO, Pascual, Tuy en la Baja Edad Media. Siglos XII-XV, Santiago 1923, 34).

56 "El poblamiento urbano en la Galicia medieval", 377.

57 "Antología de textos forales de Galicia", 329-31.

58 Introducción al fenómeno urbano medieval gallego, 38-39.

59 GONZÁLEZ PAZ, Carlos A., "O desenvolvemento urbano medieval na costa cantábrica lucense: o nacemento e consolidación da vila de Ribadeo", Murguía. Revista galega de Historia, 11 (2004), $17-31$.

60 "El poblamiento urbano en la Galicia medieval", 385. 
gueses locales, concediéndosele el Fuero de Allariz ${ }^{61}$. No se le conoce un alfoz, en parte posiblemente por la cercanía del Monasterio de Santa María de Melón, que pudiera ejercer una importante presión señorial sobre la zona.

El último aforamiento de este monarca será el de Bonoburgo de Caldelas ${ }^{62}$, una villa de segundo orden fundada posiblemente sobre un praesidium romano en la importante vía de comunicación entre Orense y Ponferrada. A este enclave, en 1172 se le concede un fuero breve por medio del cual se le extiende el de Allariz, que reproducía íntegramente, concesión que confirmaría Alfonso IX en $1228^{63}$. parece ser, pues, el modelo foral para las labores de repoblación y creación urbanas en el interior de Galicia, en unos mismos circuitos económicos.

Las restantes actuaciones de Fernando II son simples confirmaciones de fueros otorgados con anterioridad como son las del fuero de Lugo en 1159 y 1177, sucesivamente.

La labor urbanizadora de la región gallega realizada por Fernando II fue continuada por su hijo y sucesor Alfonso IX, hasta el punto de convertirse en el mayor benefactor de la Galicia urbana. Él tendrá mayor fortuna a la hora de fundar villas que permanezcan en el realengo, especialmente en la fachada costera "por utilidad al reino" "64. Estos nuevos puertos estarán ya menos presionados por el peso de Santiago y sus peregrinaciones, orientándose ya generalmente desde un principio hacia el tráfico comercial con Inglaterra, Flandes y la costa francesa del Golfo, e incluso más adelante con el Mediterráneo. No obstante, será frecuente la necesidad de compensar económicamente a la Mitra compostelana y a otros señoríos monásticos por los posibles perjuicios que podían recibir a consecuencia de tales pueblas.

Una de sus primeras actuaciones será la recuperación para el realengo en 1198 de Ribadeo, apenas dieciséis años después de su fundación, desvinculándolo del señorío de la sede mindoniense a cambio de una participación en las rentas del burgo. Camina entonces Ribadeo hacia su consolidación, superando su fase inicial de nacimiento. Se consolida y medra rápidamente, bendecida por su actividad portuaria, y muestra de ello son las dos ampliaciones de su alfoz que adquiere en sus primeros años de existencia.

A continuación, hacia 1200, funda la villa de Vivero, villa cuyo documento foral no nos ha llegado y que posee tal vez la mayor penuria informativa de las villas de la Marina lucense. Es muy probable que se tratase de una fundación completa-

\footnotetext{
61 "Antología de textos forales de Galicia", 327-29.

62 Hoy Castro Caldelas.

63 "Antología de textos forales de Galicia", 281-83.

64 "Pro utilitate regni mei"
} 
mente nueva en la Terra de Vivario trasladando la feligresía de San Pedro de Vivero al emplazamiento actual en torno al puerto y el Pontem Vivario que pronto se construiría ${ }^{65}$, aunque es probable rastrear actuaciones regias en la región anteriores a la fundación ${ }^{66}$. Alfonso IX alentará la construcción de la muralla y concederá grandes favores y franquicias para su despertar económico frente a la sede mindoniense. En consecuencia serán habituales las tensiones, produciéndose sucesivos pactos entre las jurisdicciones realenga, señoriales y concejil acerca de las rentas y la autoridad y valiéndole esto la oposición del episcopado y el respaldo de la monarquía. No obstante, con el tiempo pasaría a depender del señorío del obispo en fecha incierta ${ }^{67}$.

Las siguientes actuaciones del rey leonés en la costa gallega serán en su sector más meridional, también al filo del siglo XIII. Se trata de dos fundaciones que, a la vez, cumplen la función de enclave portuario para la explotación marítima pero por su posición estratégica contribuyen al fortalecimiento del sector fronterizo con Portugal. Hablamos primeramente de La Guardia, aforada en torno a 1200 y aún muy poco investigada ${ }^{68}$. El primer testimonio que hace alusión a La Gurdia data de 1195, nombrándose a un juez de la villa, que acredita su carácter urbano por las actividades económicas de corte comercial que se realizan en ella ${ }^{69}$.

Más conocida resulta historia de la segunda de estas fundaciones, la ciudad de Bayona, fundada tras la expropiación real al monasterio de Oya del coto de Erizana para fundar allí una villa ${ }^{70}$. Tras compensar al monasterio con parte de las rentas del nuevo núcleo, a éste le concede Alfonso IX en mayo de 1201 un fuero propio que se conserva fragmentariamente ${ }^{71}$. Del contenido del mismo se desprende la marcada vocación mercantil con que nace Bayona, que se ve muy pronto beneficiada con privilegios como una feria mensual, la exención del portazgo en todo el reino, muy generosos aranceles cobre la producción textil... Sin embargo, ya el propio topónimo, en relación con la Bayona gascona, da cuenta además de su carácter claramente limitáneo, como ocurre con el topónimo militar de La Guardia.

\footnotetext{
65 Introducción al fenómeno urbano medieval gallego, 43-44.

66 GARCÍA ORO, José, "Vivero en los siglos XIV y XV. La colección diplomática de Santo Domingo de Vivero", Estudios Mindonienses, 3, 1987, 11-131, 12-14; y CAL PARDO, Enrique, "De Vivero en la Edad Media", Estudios Mindonienses, 7 (1991), 11-226, 12-15.

67 Introducción al fenómeno urbano medieval gallego, 42.

68 PORTELA SILVA, Ermelindo, La región del obispado de Tuy en los siglos XII a XV. Una sociedad en la expansión y en la crisis, Santiago de Compostela, 1976, 93.

69 Íbid. 177.

70 GONZÁLEZ, Julio, Alfonso IX, 1, 247.

71 "Antología de textos forales de Galicia”, 279-81.
} 
Sin embargo, la gran creación de este monarca en la fachada litoral galaica será la fundación en 1208 de La Coruña. Para ello se servirá de un pequeño burgo portuario situado alrededor de un viejo faro en el fondo del saco de la ría que se había constituido en época del Emperador y sustituía otro precedente de época romana en las cercanías - el Burgo de Faro-, un pequeño puerto que capta el tráfico franco por su excepcional posición en las rutas atlánticas y que despierta el recelo de los arzobispos compostelanos al robar tráfico marítimo a Padrón. En junio de 1208 Alfonso IX hace una concesión a la iglesia de Santiago de cien marcas anuales deducidas del portazgo de La Coruña, aludiendo en dicha concesión a la construcción de una villa "in loco qui dicitur Crunia", un nuevo puerto de Faro que vuelve al antiguo emplazamiento romano, dominado por la Torre de Hércules y un castillo, y que supondrá la agonía del Burgo como núcleo, si es que alguna vez llegó a alcanzar una cierta entidad urbana. El primer texto foral de la nueva ciudad es un fuero breve que extendía el fuero de Benavente ese mismo mes de junio $^{72}$. Se le reconocía la existencia de un concejo que protagonizaría un gran desarrollo en las décadas siguientes ${ }^{73}$ al que se le atribuyen importantes derechos para su subsistencia y se le preservaría de la intervención de los poderes señoriales. La fundación tropezaría al principio con algunas dificultades, especialmente desde la Iglesia compostelana y el monasterio de Sobrado, a los que hubo que compensar junto a la encomienda templaria emplazada en la zona ${ }^{74}$. Pero terminará por consolidarse, con una boyante actividad portuaria que pronto le hará desarrollar un arrabal que aglutinara estas actividades -la Pescadería- y la convertirá en uno de los puertos más importantes de desembarco de peregrinos, ofreciendo más facilidades que Noya y Padrón y emplazándose en una escala obligada de los circuitos atlánticos.

Conocemos por el fuero concedido a Parga la promoción, con anterioridad a 1225, de otro enclave portuario en la ría del Burgo de personal historia: Betanzos. Será compañera de destino de La Coruña, aunque siempre por detrás de ella. Parece ser que los habitantes del concejo de Villanova de Bitanciis elevan al monarca en 1219 la petición del traslado de su núcleo urbano al actual emplazamiento del Castro de Unctia, entre los ríos Mandeo y Mende, y su promoción al rango de villa, llevándose consigo su antiguo nombre. Los pobladores buscaban mejor emplazamiento para sus necesidades defensivas y económicas, el monarca accederá y

72 “Antología de textos forales de Galicia”, 289.

73 SÁNCHEZ CHOUZA, José Manuel, A Coruña en la Baja Edad Media, La Coruña 2005, 141-59.

74 BARRAL RIVADULLA, Dolores, La Coruña en los siglos XIII al XV. Historia y configuración urbana de una villa de realengo en la Galicia medieval, La Coruña 1997, 27-30. 
extenderá poco antes de 1225 el Fuero de Benavente a la nueva villa. El nuevo lugar pertenecía al monasterio de Sobrado, quien recibiría en compensación parte de sus rentas $^{75}$. Los primeros años de organización concejil, aunque difíciles, desvelarán un potencial económico en parte coartado por la cercanía del potente puerto coruñés, así como el continuo favor de los monarcas, que acrecentará en época de los Trastámara y la presión de la casa de Andrade en la villa ${ }^{76}$.

Una última fundación costera alfonsina será la puebla de Santa Marta de Ortigueira en la tierra de Ortigaria con una intención claramente económico-comercial. Encontramos ya certeza documental de su existencia en $1235^{77}$ sobre la base de dos parroquias en la zona, pero habrá que esperar hasta tiempos de Fernando III para ver una fundación efectiva ${ }^{78}$ y hasta 1255 para asistir a la concesión a la villa del Fuero de Benavente por Alfonso $\mathrm{X}^{79}$.

Es también preocupación de Alfonso IX la línea fronteriza con Portugal, una frontera que se anunciaba ya conflictiva desde antes de la escisión, con una amenaza que obliga a desenvolver una política de fortalecimiento consistente en una dinámica fundacional a la manera de una carrera entre los monarcas portugueses y leoneses por afianzar la raya con castillos que se urbanizarán en el reinado de Alfonso IX fundamentalmente. Ya en la concesión del fuero a la ciudad tudense Fernando II hacía una clara declaración programática: "para la defensa del reino -dirá el monarca- no era suficiente el combate con las armas, sino que también se necesitaba construir ciudades y pueblos muy bien defendidos con el fin de que no se conturbasen ante los ataques de los enemigos" $" 80$.

Ya se ha hablado del carácter limitáneo-militar de Bayona y La Guardia al tratar de su faceta como villas portuarias, que vienen a aumentar la densidad urbana en la línea junto a Allariz y Tuy. Alfonso IX vendrá a acrecentar la presencia urbana con la fundación de las villas de Milmanda, Lobera y Salvatierra. La localidad de Milmanda, en las cercanías de Celanova, recibe un fuero breve en el año 1199 que le remite al fuero benaventano ${ }^{81}$, con un emplazamiento estratégico frente al asentamiento portugués de Castro Laboreiro. Por su parte, la cercana localidad

75 GARCÍA ORO, José, “Betanzos en la Baja Edad Media”, Anuario brigantino, 7 (1984), 21-32, 21-24.

76 Íbid. 24-26.

77 "El poblamiento urbano en la Galicia medieval", 397.

78 RAMIL GONZÁLEZ, Emilio-BREIXO RODRÍGUEZ, X. Carlos - GRANDÍO SEOANE, Emilio, Historia de Ortigueira, La Coruña 1999.

79 MACIÑEIRA Y PARDO, Federico, Crónicas de Ortigueira, La Coruña 1892,268-273.

${ }^{80}$ Tuy en la Baja Edad Media, doc. n ${ }^{\circ} 8$.

81 "Antología de textos forales de Galicia", 300-02. 
orensana de Lobera recibirá en junio de 1228 su carta foral ${ }^{82}$. Asimismo, en 1228 se afora también Salvatierra sobre el río Miño y frente a la fortaleza portuguesa de Monçâo. ${ }^{83}$ Finalmente, un capítulo peculiar entre estas villas es la fundación de Verín, con una actitud inicialmente comercial en el paso obligado entre Portugal y Galicia que va tomando también tintes militares, que se puede datar a partir de 1185, cuando el abad Payo de Celanova concede una carta de población a los que acudiesen a vivir a la villa con generosos privilegios y franquicias. ${ }^{84}$ Se trata de núcleos pequeños que en absoluto alcanzarán un gran desarrollo urbano, de vida azarosa y marcada función militar y, en un segundo plano, comercial. "La frontera les traerá de todo: entradas devastadoras de los portugueses, pero al mismo tiempo un tráfico que será vital para su vida mercantil. Las relaciones de vecinos y sus intercambios a ambos lados de la raya serán más fuertes que la voluntad de sus monarcas"85.

Otro de los frentes que acometerá Alfonso IX en su repoblación, continuando la labor de su padre, será la promoción urbana del interior de Galicia. En este contexto parece aforar el Burgo del Valle de Oro -hoy Castro de Oro- en torno a una fortaleza en 1220; así como en 1225 concede el Fuero de Benavente a través de la versión que poco antes había otorgado a la villa asturiana de Llanes a la puebla de Parga, en el territorio de Parrega ${ }^{86}$. Por último, en 1228 confirmará la carta foral de Bonoburgo de Caldelas en una versión romanceada ${ }^{87}$.

Dentro de esta repoblación interior podemos distinguir un grupo de actuaciones urbanas con una identidad propia, pues aparte de la propia función de ejercer como centro organizador de un territorio, serán realidades urbanas con un cometido especial en la creación de etapas en el camino a Compostela, especialmente en el eje del Camino Francés ${ }^{88}$. Estas localidades, en ocasiones tradicionales centros territoriales con castillo del tenente, se desarrollarán bajo el estímulo del tránsito de peregrinos, dando lugar a una tipología y morfología propia marcada por la presencia del eje viario ${ }^{89}$.

82 Íbid. 290.

${ }^{83}$ La región del obispado de Tuy en los siglos XII a XV, 178-79.

84 "Antología de textos forales de Galicia", 341-342.

85 "El poblamiento urbano en la Galicia medieval", 394.

86 "Antología de textos forales de Galicia", 314-17.

87 Íbid. 281-83.

88 "Repoblaciones en el Camino de Santiago" (cit. supra nota 9).

89 PASSINI, Jean, "Morfología urbana de las poblaciones del Camino de Santiago", Las peregrinaciones a Santiago de Compostela y San Salvador de Oviedo en la Edad Media. Actas del Congreso Internacional celebrado en Oviedo del 3 al 7 de diciembre de 1990, Oviedo 1933, 257-268. 
La primera de las fundaciones alfonsinas al respecto puede ser precisamente la más prototípica de todas. La villa de Melide se sitúa en la ruta jacobea como tradicional etapa de la antigua vía desde, seguramente sobre la villa rural de Meliti. Aparece con sentido urbano en la documentación desde al menos 1164, posiblemente por un componente franco que se avecina conformando un primer burgo. En 1213 Alfonso IX le da una categoría de villa trasladando su emplazamiento bajo el castro y ahora castillo ${ }^{90}$. Desarrolla desde entonces la forma propia de una villa de camino, con una muralla documentado y con el eje viario como calle principal, donde también se dispone la iglesia parroquial de San Pedro y un hospital para peregrinos extramros desde época bajomedieval. La villa se convierte pronto en una de las mejores y más lucrativas villas del interior gallego, gracias a su orientación claramente comercial. El concejo aparece en funciones, pese a ser sometida a la Mitra compostelana y tener parte de sus rentas el monasterio de Sobrado.

La siguiente promoción en el Camino será Triacastela, una región acéfala por la existencia de "tres castillos" que le dan su nombre. Entre las muchas parroquias que existen en ella, por una pasa la ruta jacobea, por lo que desde 1149 poderosos monasterios como Samos van tomando posiciones.Se irá conformando un burgo que, junto con la parroquia preexistente de Santa María de Triacastela, se va apropiando del nombre del territorio y convirtiéndose en centro de su alfoz ${ }^{91}$. Hacia 1213 Alfonso IX reconoce su categoría urbana atraído por su estratégica posición junto a la montaña gallega.

Por último, en 1228 aparece ya fundada la última de estas villas camineras, Villanueva de Sarria. Se trata de una villa fundada nuevamente sobre un antiguo emplazamiento castral que, cuando se convierte en una villa en la ruta a Santiago, la villa que allí se forma atraerá el camino de peregrinos y lo convertirá en su calle principal $^{92}$. Esto es lo poco que conocemos de su historia, pues no aparece en los primeros documentos jacobeos. Es muy posible que se formase a partir de la fortaleza, un hospital de peregrinos y un pequeño monasterio. Un documento de 1228 "in villa nova de Sarria" nos da la primera mención como núcleo urbano ${ }^{93}$, lo que parece indicar la existencia de un poblamiento anterior sobre el río Sarria. Será una villa producto netamente del fenómeno peregrinatorio que, pese a no pasar de un segundo orden, desarrollará toda una infraestructura para la atención del viajero: hospitales de peregrinos y leprosos, mercado...

\footnotetext{
90 "El poblamiento urbano en la Galicia medieval", 392.

91 Íbid. 389.

92 "Morfología urbana de las poblaciones del Camino de Santiago", 263.

93 Alfonso IX, doc. n $574-575$.
} 
Por último, otras actuaciones de Alfonso IX serán simples confirmaciones de fueros otorgados en época anterior como en el caso de Lugo por dos ocasiones, en 1207 y en 1225, o la renovación del fuero de Tuy con nuevos privilegios en $1211^{94}$.

En el transcurso de los poco más de setenta y tres años que comprenden los reinados de Fernando II y Alfonso IX sobre León, y merced a la política de promoción urbana que habían desplegado, se había operado una transformación sustancial de las estructuras de la región galaica, tanto en los aspectos jurídicos como socioeconómicos y político-administrativos. Donde antes hubiera tan sólo cinco ciudades episcopales de una realidad urbana aún en formación, con la reunificación de la Corona de Castilla a la muerte de Alfonso IX, su sucesor Fernando III hereda una Galicia ya plenamente urbanizada con casi una treintena de núcleos que podemos considerar urbanos.

\subsection{Tercera etapa: Los momentos finales con Alfonso X y Sancho IV (1230-1295)}

Con el acceso al trono de Fernando III "el Santo" se produce la reunificación de León y Castilla, pero también la recuperación del interés por la expansión meridional en la misión histórica de la Reconquista. El Rey Santo no prestará apenas atención a las repoblaciones interiores de las regiones norteñas, centrándose más bien en la recuperación y repoblación de tierras andaluzas. Durante su reinado tan sólo se producirán diferentes confirmaciones sobre fueros en localidades ya consolidadas como Lugo ${ }^{95}$ y Bayona en 1232 o Tuy en $1254^{96}$.

No ocurrirá lo mismo, en cambio, desde comienzos del reinado de Alfonso X. El Rey Sabio retomará la acción urbana en Galicia tras el paréntesis impuesto por su padre, aunque no lo revestirá ahora tanta importancia como en época anterior o como en esos momentos en otros territorios del norte peninsular como Asturias o Guipúzcoa, donde se estaba produciendo entonces el principal impulso al proceso urbanizador. Esto, sin duda alguna, hubo de deberse a que en la zona gallega la empresa de promoción ya había cuajado tiempo atrás, dando sus mejores y más tempranos frutos aquí. No obstante, no quedaron excluidos completamente del programa del Rey Sabio estos territorios. La orla costera se beneficiará con dos nuevas fundaciones regias: una ya conocida, el aforamiento de Santa Marta de Ortigueira en 1255; y otra, la fundación de la villa de Puentedeume en la desembocadura del río de mismo nombre, que afora en 1270 según el Fuero de

\footnotetext{
94 "Antología de textos forales de Galicia", 335-36.

95 Íbid. 291-94.

96 Íbid. 336-41.
} 
Benavente $^{97}$ a petición de los vecinos para poner orden en el territorio acosado por los señores vecinos. Una última actuación alfonsina será la fundación de una nueva villa fronteriza sobre la ruta desde Chaves en Monterrey en 1265. Asimismo, en algún momento confirma los fueros de Pontevedra. Posiblemente también se deban a Alfonso X la iniciativa de fundación de otros núcleos menores, apenas considerables como urbanos, como puedan ser los pequeños puertos de Cedeira, Neda y Redondela o las pueblas del interior lucense sobre el camino asturiano a Santiago de Balonga y Burón.

Por otro lado, durante su reinado asistimos a la creación por parte del arzobispo compostelano Juan Arias en 1254 de la villa de Caldas de Reyes, tratando de atraer a sus moradores a la villa situada en la Tierra de Santiago para consolidar su población sobre un asentamiento con origen en una mansio romana con continuidad en época sueva ${ }^{98}$. Por ello, son constantes las exenciones tributarias y las limitaciones al realengo y señorío para garantizar la paz de los vecinos, constituyendo un cuerpo jurídico muy favorable ${ }^{99}$. En el camino portugués a Santiago, Caldas se encuentra en un emplazamiento privilegiado que lo hace partícipe de toda una corriente mercantil y peregrinatoria en contacto con los florecientes enclaves portuarios de Tuy, Pontevedra y Padrón y lugar de intercambio con el interior. El mismo Juan Arias será el que extienda en algún momento de su episcopado extienda a Noya los fueros de Pontevedra con correcciones y añadidos ${ }^{100}$.

La última fundación en Galicia será la Puebla de Muro, San Pedro de Muro o simplemente Muros. Se trata de una puebla menor cuyo nacimiento cabe situarlo como una de las pueblas menores proyectadas en el litoral por Alfonso IX $^{101} \mathrm{o}$ incluso por Alfonso $\mathrm{X}^{102}$. En cualquier caso, este proyecto parece ser que fracasó, pues no se vuelve a mencionar la villa hasta que Sancho IV la puebla -o "repuebla"- a Fuero de Benavente ${ }^{103}$ en 1286 en el contexto de un viaje del monarca por tierras gallegas y que acaso pretendiera una villa de realengo que equilibrar la presencia episcopal de Noya en la ría de su nombre ${ }^{104}$. Sin embargo, apenas quince

97 Íbid. 317-21.

98 "El poblamiento urbano en la Galicia medieval", 393.

99 "Antología de textos forales de Galicia", 284-85.

100 Íbid. 304-307

101 Galicia en los siglos XIV y XV, 183.

102 "El poblamiento urbano en la Galicia medieval", 398. En la carta de Fernando IV y María de Molina de agosto de 1299 se habla de Muros "con todo su alfoz e con aquellos terminos que dio el Rey Don Alfonso quando la poblo" (Fueros de Santiago, cit, supra nota 30, 528-29).

103 "Antología de textos forales de Galicia", 302-03.

104 Galicia en los siglos XIV y XV, 184-85. 
años después, con la monarquía castellana atravesando la minoría de edad de Fernando IV, doña María de Molina se ganaba el apoyo de la Mitra compostelana cediéndole el control sobre la villa de Muros, que hacía competencia a Noya.

Con estas actuaciones se cerraba la promoción urbana de Galicia, un territorio apenas dos siglos antes completamente descentralizado, con la única presencia de unas difusas realidades urbanas relacionadas con las mitras episcopales, que ahora se veía cubierta de una constelación de villas al servicio de los intereses de la monarquía o de los señoríos eclesiásticos, que competían entre sí. A todas estas ciudades y villas hay que sumar las realidades cuasi urbanas que aparecen, especialmente en la costa para la explotación pesquera como son los "portos" de mar -puertos de mar o pesquerías fundados por los señores laicos o monacales para el aprovechamiento pesquero, como Portonovo, Rianxo, Fefiñanes, Cambados, Santo Tomé, Vigo, Cangas de Morrazo, Muxía, Laxe, Foz...- y las pequeñas villas surgidas en torno al fenómeno jacobeo de las peregrinaciones para la atención de peregrinos pero que no alcanzan una categoría superior -Palas de Rey, Portomarín, Leboreiro, Arzúa, Fonsagrada...-.

\section{CARACTERÍSTICAS GENERALES DE LOS NUEVOS NÚCLEOS Y DEL PROCESO FUNDACIONAL}

Pese a la heterogeneidad de tiempos, espacios, protagonistas e intenciones que se dan a lo largo de todo el proceso descrito y que dieron lugar a inevitables variantes locales en el tiempo y el espacio, parece posible establecer una serie de rasgos comunes que permiten, sin caer en la excesiva generalización, tratar el fenómeno como manifestaciones de una misma realidad histórica.

En primer lugar, se debe señalar como algo generalizado la titularidad de las fundaciones como exclusiva de los monarcas, ocupando un lugar principal entre sus acciones de gobierno. Solamente encontramos algunos casos aislados de fundaciones urbanas de iniciativa señorial, como pueden ser Caldas y Verín. Frecuentemente, los monarcas hacían uso de esta facultad privativa previa petición de los habitantes de un primer núcleo -Ribadavia, Betanzos, Puentedeume-, pero la iniciativa es siempre exclusiva del poder superior, quien es capaz de dirigir el proceso repoblador y conceder un estatuto jurídico privilegiado a los nuevos villanos así como dirimir los posibles conflictos que surjan por la repoblación. Esto no quita que, una vez fundada por la autoridad regia, la nueva realidad sea inmediatamente entregada a un poder señorial. 
Asimismo, un principio de exclusivismo local parece presidir todas las fundaciones, pues las concesiones regias son los miembros de una determinada colectividad localizada en una base territorial concreta, y siempre incompatibles con la condición de privilegiado. Las cláusulas de incorporación de vecinos a nuevos villazgos son más laxas en las poblaciones de frontera, previéndose en algunos casos la incorporación de elementos foráneos a la colectividad, o incluso en las villas de la ruta jacobea, frente a las comunidades de francigeni. De hecho, frente a las repoblaciones más meridionales o del Camino de Santiago en sus sectores navarro, castellano y leonés, las fundaciones urbanas gallegas -como las del norte peninsular en general- se hacen con una base demográfica muy pequeña, con moradores tradicionales de la comarca, no conllevando por tanto migraciones de largo recorrido. Es, pues, más un proceso de reorganización social de un territorio desarticulado que una repoblación en el sentido más literal del concepto. Esto no implica que una vez superada la etapa fundacional, consolidada ya la realidad urbana, su propia dinámica atraiga la incorporación de elementos foráneos e incluso extranjeros, como las villas marítimas de animada actividad comercial.

Asimismo, se habla siempre de "creación" de las nuevas villas en oposición a las de formación espontánea. Esto es, las villas gallegas responden a un deseo consciente del poder superior y no son fruto de un simple avencindamiento espontáneo de un grupo como sí pudieron ser la mayoría de las realidades preurbanas -los burgos- sobre los que se desarrollan las nuevas fundaciones. No se puede confundir ello con una creación ex novo o ex nihilo, que aunque existen proyecciones sobre un lugar despoblado, no dejan de ser extrañas en el proceso, en que generalmente se escoge para el asentamiento de la villa un establecimiento local preexistente al que se le confiere el nuevo rango urbano.

Las nuevas villas gallegas compartirán unos elementos comunes, que son precisamente los que le confieren esa categoría de realidades urbanas en el contexto del renacimiento de la ciudad que se vive en toda Europa desde el siglo XI. El primero de ellos, tal vez el más visible aún, atañe a su morfología y plano. Si bien puede hablarse de diferentes modelos según la categoría del núcleo en cuestión, con un elemento definitorio y generalmente centralizador de cada uno -la catedral en las civitas episcopales, el puerto en las villas costeras, el castillo o fortaleza de las ciudades de frontera, la calle principal en la ruta a Santiago en las localidades del Camino...-, la mayoría de las villas suelen disponer de un plano que, adaptándose a las necesidades que impone el terreno, se encierra en torno a una muralla o cerca que tiene la doble función de reforzar el carácter concentrado del poblamiento y servir de nítida separación respecto del mundo campesino circundante. En su inte- 
rior, el poblamiento se articula en torno a calles y plazas, en torno a las cuales se agolpan las casas y otros edificios característicos como son las iglesias parroquiales, que acaban constituyendo las futuras separaciones en barrios más allá de la compacidad global. Extramuros podrán extenderse posibles arrabales, que en ocasiones aglutinaran a los trabajadores de un mismo sector -caso de los arrabales pescadores de la Pescadería en La Coruña y Moureira en Pontevedra- y las tierras de explotación comunal como bosques o montes, y será donde se asienten los conventos de órdenes mendicantes que reflejan un estatus urbano ya plenamente consolidado.

Es de suma importancia como definidor de la comunidad urbana la actividad económica de sus habitantes. Una parte muy importante de los mismos vive de sus oficios artesanos, del comercio y de los servicios. Por eso es de capital importancia la existencia en la villa de un mercado y de una feria, especialmente en las villas de interior que no viven el ininterrumpido tráfico comercial de los puertos. El mercado, además, pone en relación el mundo urbano con el mundo rural, resaltando la capacidad ordenadora de la comarca.

Esto provocará la existencia en la ciudad de un determinado perfil en la sociedad, conformada mayoritariamente por la figura del "burgués". Éste vive dedicado a su actividad económica, nunca relacionada con la agricultura o la ganadería, sino más bien con la artesanía o el comercio. Pronto aparecerán las primeras corporaciones de oficios, una organización profesional que se sirve de las cofradías para la defensa de sus intereses.

Otro elemento común es la participación por parte de los habitantes de un estatuto jurídico ciertamente privilegiado y exclusivo de la comunidad, plasmado en la carta foral y sus posteriores ampliaciones y confirmaciones. En estos textos se regula la forma de gobierno, fundamentada en el concejo de los vecinos y con unas instituciones que se repiten -alcaldes, jueces, notarios, pregonero...-, pero con variaciones si la ciudad no es de realengo sino está sometida a algún tipo de señorío, que se suele hacer presente en la villa ya sea personalmente o mediante delegados. No obstante, esta existencia del estatuto no implica que fuera respetado, especialmente en la época bajomedieval, en que los acontecimientos harán de las villas gallegas objetos de codicia por parte de las casas nobiliarias, que se introducen en sus cuadros municipales y acaban monopolizando el poder y socavando la soberanía del concejo. Como se ha visto, la presencia de los señoríos episcopales es enorme, especialmente el de Santiago, que aspira a monopolizar el tráfico marítimo en los puertos de su dominio, por lo que no es extraño que muchas de las nuevas villas acaben pasando a su autoridad pese a haber nacido como realengas -Noya, Padrón, Vivero, Ribadeo, Pontevedra...-. Otra posibilidad también común es la entrega, 
especialmente con Enrique II y los siguientes Trastámara, de las villas de realengo en pago a su ayuda a señores particulares que harán de ellas su señorío solariego.

Finalmente, este devenir histórico bajomedieval en el caso gallego implicará la lucha por la soberanía en las urbes. El movimiento urbano encierra un carácter revolucionario, pues en su plena realización entraña la liquidación del modelo feudal, y la lucha urbana es inseparable del proceso de consolidación del poder regio frente al modelo señorial. Por medio de las hermandades de ciudades el movimiento urbano gallego será capaz de llevar adelante la movilización más original y consistente, desde las primeras protestas en la Compostela de Gelmírez hasta la confrontación definitiva en la revuelta Irmandiña del siglo XV. Pero fue una lucha "de gorriones contra halcones" y los señoríos acabaron por recuperar sus poderes jurisdiccionales con que caminan ya dirigiéndose a la Edad Moderna.

\section{LA INVESTIGACIÓN DEL FENÓMENO MEDIEVAL URBANO GALLEGO}

El fenómeno urbano gallego, pese a quizá parecer una manifestación mediocre de un proceso europeo como es el renacimiento de las ciudades superado el año 1000, es en sí mismo una realidad histórica sumamente compleja que constituye un objeto de estudio necesario de investigación. Lejos de un reduccionismo que vea en él un fenómeno bastardo alejados de los conceptos clásicos de "burgués" y "ciudad", las nuevas villas gallegas son núcleos urbanos en el sentido pleno que, íntimamente relacionados con la sociedad rural en que se ven inmersos y el sistema feudal imperante, iluminan el panorama señorial de la Galicia medieval que merece la pena conocer.

No obstante, es un proceso histórico que, largo en el tiempo y en la extensión geográfica que cubre, presenta un difícil entramado desde cualquier punto en que intentemos acometerlo: unas circunstancias únicas en la génesis de cada villa en ocasiones envueltas en la leyenda, una tipología difusa plagada de excepciones y peculiares simbiosis, unos casos límite con una frontera muy difícil entre lo urbano y lo rural... A ello se le une la precariedad de unas fuentes en muchas ocasiones inexistente.

En estas circunstancias, no es de extrañar que un trabajo de síntesis sobre el fenómeno en el estado actual de la investigación no pueda aspirar a más que un análisis diacrónico y puramente informativo como el que se pretende en este artículo. De hecho este tratamiento tampoco es tarea fácil, debido a las grandes lagunas de la historiografía previa, y el presente texto es poco menos de lo que se conoce en la actualidad sobre la historia urbana en la Galicia medieval. 
La investigación se encuentra su primer escollo a la hora de enfrentarse a la realidad de las fuentes. Apenas conservamos fuentes, directas o indirectas, para la inmensa mayoría de las villas, salvo quizás el caso de Orense, que ha conservado un gran volumen de información que permite la elaboración de monografías sobre su historia. Puede también tenerse en estima las fuentes conservadas respecto a Santiago, Pontevedra y La Coruña, pero para el resto de poblaciones el silencio es prácticamente absoluto. Ya se ha podido observar la deficiencia de los textos forales conocidos, muchos de ellos a través de menciones en otros o incluso por confirmaciones muy posteriores al original que son susceptibles de haber sido transformados de alguna forma. Lo mismo ocurre con la documentación notarial, conociéndose sólo algunos de los protocolos relativos a negocios sobre bienes inmuebles que apenas nos hablan de las compraventas diarias y de las actividades económicas de la ciudad.

Sin embargo, aunque se haya conservado tan poca documentación, este volumen es considerablemente mayor en comparación con el de otras regiones vecinas como Asturias, especialmente si tenemos en cuenta la riqueza de sus fondos monásticos. El principal problema es el trato que esta documentación ha venido recibiendo, pues normalmente se ha procedido a su edición simplemente a modo de apéndice documental o diplomatario de algunas de las monografías al respecto, pero ni siquiera de todas. Esto implica el silenciamiento de mucha documentación que no siendo útil para acompañar el texto se desecha. Resulta conveniente la edición más depurada de estas fuentes y de toda la documentación municipal gallega, ahora mismo dispersa en obras y archivos, para constituir un corpus verdaderamente útil al investigador. Los propios textos forales no cuentan con otra edición que la magna obra decimonónica de Antonio López Ferreiro ${ }^{105}$, o incluso a través de las referencias que brinda el utilísimo catálogo de fueros y costumbres municipales editado hace ya veinte años por Ana $\mathrm{M}^{\mathrm{a}}$ Barrero y $\mathrm{M}^{\mathrm{a}}$ Luz Alonso ${ }^{106}$, aunque la reciente publicación de una antología que recoge la mayoría de ellos con un serio aparato crítico de Faustino Martínez Martínez ${ }^{107}$ es enormemente loable. La tarea de publicación de fuentes ha de seguir la tarea, en especial atendiendo a la documentación monástica. Resultan atrevidas, pero muy acertadas, las recientes palabras de un joven investigador respecto a la situación inédita de parte de la documentación del monasterio de Melón: "Esta situación, lejos de ser singular, constituye, por desgra-

105 Fueros de Santiago.

106 BARRERO GARCÍA, Ana María - ALONSO MARTÍN, Ma Luz, Textos de derecho local español en la Edad Media. Catálogo de fueros y costums municipales, Madrid 1989.

107 "Antología de textos forales de Galicia". 
cia, una generalidad penosa en la historiografía gallega. Y todavía asombra comprobar cómo la edición de fuentes sigue generando indiferencia entre círculos académicos presuntamente 'renovadores' de la denominada 'historia tradicional', practicando una 'historia' pretendidamente innovadora que bajo títulos ampulosos generalmente poco aporta a la comprensión del pasado" 108 .

Otro obstáculo que se encuentra la historia urbana es estar tradicionalmente aquejada de una tendencia en muchas ocasiones a la simple "historia local" que produce narraciones lineales y desarticuladas que no pasan de ser meras crónicas de acontecimientos que suceden en torno a un núcleo urbano, más que una historia propiamente dicha del núcleo en cuestión. Estas historias locales pecan en ocasiones de falta de método histórico, confusión de las realidades geográficas, la no referencia a las fuente empleadas... Además es frecuente la figura del erudito local interesado por las "antigüedades" de su villa que elabora una historia muy tradicional y en ocasiones mezclada con la leyenda, que contrariamente a lo que algunos piensan se da incluso en la actualidad. No obstante no podemos generalizar en ello, pues bien es cierto que existen obras de este tipo de gran valor para el historiador científico, transmitiendo noticias que de otro modo podrían considerarse perdidas.

El primer intento según unos planteamientos metodológicos netamente históricos de aproximación al fenómeno urbano medieval en Galicia es la obra de Fernando López Alsina sobre las tres localidades de la Marina lucense -Mondoñedo, Vivero y Ribadeo-, de $1976^{109}$. Tras él, se produjeron otros acercamientos al asunto desde una perspectiva más regional, como en el caso de las villas meridionales a través del estudio del obispado tudense ${ }^{110}$. Se abordaría también en su relación con el fenómeno feudal ${ }^{111}$ y con los señores gallegos a la búsqueda del control urbano ${ }^{112}$.

Desde entonces se sucedieron las monografías extensas que, con un modelo similar, abordan la formación histórica, la composición social, la coyuntura económica, la morfología, el entramado institucional de una ciudad de una manera la mayoría de las veces directa y rigurosa. Inauguró de nuevo el género López Alsina

108 ROMANí MARTÍNEZ, Miguel - OTERO PIÑEIRO MASEDA, Pablo S., "La "domus" de Santa Leocadia de Guillade (Ponteareas) en un documento del año 963. Estudio sobre su autenticidad", Cuadernos de Estudios Gallegos (actualmente en prensa).

109 Introducción al fenómeno urbano medieval gallego.

110 La región del obispado de Tuy en los siglos XII a XV y, a continuación, SÁNCHEZ CARRERA, Mª Carmen, El Bajo Miño en el siglo XV. El espacio y los hombres, La Coruña 1997.

111 PALLARES MÉNDEZ, M $M^{\text {a }}$ Carmen, "Sistema feudal y proceso de urbanización: algunas reflexiones a propósito del caso gallego en los siglos XII y XIII", Jubilatio (cit. supra nota 46), 95105; y también PORTELA SILVA, Ermelindo, "Sistema feudal y proceso de urbanización: las ciudades de Galicia ante la crisis bajomedieval", íbid. 83-93.

112 Galicia en los siglos XIV y XV. 
con su estudio sobre el núcleo compostelano en la Alta Edad Media' ${ }^{113}$, al que siguieron el de José Armas Castro sobre Pontevedra, ${ }^{114}$ la obra sobre Orense de Anselmo López Carreira ${ }^{115}$, y la monografía desde la Historia del Arte acerca de La Coruña que publicara Dolores Barral Rivadulla116, así como los libros sobre Lugo $^{117}$ y Bayona ${ }^{118}$ elaborados entre José García Oro y M $\mathrm{M}^{\mathrm{a}}$ José Portela Silva. A todos ellos debe añadirse, aunque no como una monografía dedicada al análisis de una ciudad pero sí al estudio de un aspecto tan netamente urbano como es el comercio medieval, la magna obra de Elisa Ferreira Priegue ${ }^{119}$. Muy recientemente han visto también la luz las monografías sobre Ribadavia ${ }^{120}$, Tuy ${ }^{121}$ y nuevas aportaciones a la historia de La Coruña ${ }^{122}$ y Lugo ${ }^{123}$.

Tal es la situación actual, pues se hace necesario acometer el estudio de algunas de las principales ciudades que están faltas de una monografía que nos permita conocer su pasado medieval, especialmente la ciudad de Santiago en época bajomedieval y de la última sede episcopal carente de una monografía seria, Mondoñedo. Muchas de ellas se han comenzado a estudiar a partir de artículos a los que se han referido a lo largo del texto, como Ribadeo, Padrón, Noya, Puentedeume, Betanzos o Vivero. De cara al futuro deben abordarse, tal vez con una metodología flexible, los estudios urbanos de conjunto mediante categorías tipológicas que permitan una mayor profundización en los modelos repobladores de una determinado tipo, como las villas del Camino de Santiago o las localidades de frontera.

Se trata de un trabajo duro que no reserva al investigador grandes descubrimientos, sino logros parciales que, poco a poco, vayan iluminando un poco más el panorama de la historia urbana gallega.

113 La ciudad de Santiago de Compostela.

114 Pontevedra en los siglos XII a XV.

115 Ourense no século XV. Economía e sociedade urbana na Baixa Idade Media, Vigo 1991; completada años más adelante por él mismo con Ourense no século XV. Sociedade urbana na Galicia baixomedieval, Orense 1998.

116 La Coruña en los siglos XII al XV.

117 La Iglesia y la ciudad de Lugo en la Baja Edad Media, Lugo 1997.

118 Bayona y el espacio urbano tudense en el siglo XVI: estudio histórico y colección diplomática, Santiago de Compostela 1995; y más recientemente también Baiona da Miñor en sus documentos, Vigo 2003.

119 Galicia en el comercio marítimo medieval, La Coruña 1988.

120 DEAÑO GAMALlO, Carlos A., Ribadavia y su comarca en la Baja Edad Media, La Coruña 2004.

121 VILA, Suso, A cidade de Tui durante a Baixa Idade Media, Noya 2009.

122 A Coruña en la Baja Edad Media.

123 La ciudad de Lugo en los siglos XII a XV. 


\section{CONCESIONES FORALES DE LOS REYES LEONESES A LAS CIUDADES Y NUEVAS VILLAS GALLEGAS (siglos XI-XIII)}

\begin{tabular}{|c|c|c|c|c|}
\hline FECHA & LOCALIDAD & OTORGANTE & $\begin{array}{l}\text { FAMILIA } \\
\text { FORAL }\end{array}$ & NATURALEZA \\
\hline 1019 & $\begin{array}{l}\text { Santiago de } \\
\text { Compostela }\end{array}$ & Alfonso V & León & \\
\hline $1088-1090$ & Lugo & $\begin{array}{l}\text { Alfonso VI y Raimundo de } \\
\text { Borgoña }\end{array}$ & & Perdido \\
\hline 1095 & Tuy & Raimundo de Borgoña & & Acotamiento \\
\hline 1095 & $\begin{array}{l}\text { Santiago de } \\
\text { Compostela }\end{array}$ & $\begin{array}{c}\text { Alfonso VI y Raimundo de } \\
\text { Borgoña }\end{array}$ & & \\
\hline 1105 & $\begin{array}{l}\text { Santiago de } \\
\text { Compostela }\end{array}$ & $\begin{array}{l}\text { Alfonso VI y Raimundo de } \\
\text { Borgoña }\end{array}$ & & \\
\hline $112-1126$ & Orense & Diego Velasco, obispo & & \\
\hline 1113 & Tierra de Santiago & Diego Gelmírez, arzobispo & & \\
\hline 1130 & Allariz & Alfonso VII & & Desconocido \\
\hline 1131 & Orense & Alfonso VII & $\begin{array}{l}\text { Sahagún } \\
\text { (Allariz) }\end{array}$ & \\
\hline 1142 & Tuy & Alfonso VII & Propio & \\
\hline 1152 & Allariz & Alfonso VII & Sahagún & \\
\hline 1156 & Mondoñedo & Alfonso VII & León & \\
\hline & Ferrol & Alfonso VII & & \\
\hline 1159 & Lugo & Fernando II & & \\
\hline 1164 & Ribadavia & Fernando II & $\begin{array}{l}\text { Sahagún } \\
\text { (Allariz) }\end{array}$ & \\
\hline 1164 & Padrón & Fernando II & Propio & \\
\hline 1168 & Noya & Fernando II & $\begin{array}{c}\text { León } \\
\text { (Compostela) }\end{array}$ & \\
\hline 1169 & Pontevedra & Fernando II & Propio & \\
\hline 1170 & Tuy & Fernando II & Propio & nuevo, anulando anterior \\
\hline 1170 & Tuy & Fernando II & & Restitución \\
\hline 1172 & $\begin{array}{l}\text { Bonoburgo de } \\
\text { Caldelas }\end{array}$ & Fernando II & $\begin{array}{l}\text { Sahagún } \\
\text { (Allariz) }\end{array}$ & \\
\hline 1177 & Lugo & Fernando II & & Confirmación \\
\hline 1182 & Ribadeo & Fernando II & & \\
\hline 1185 & Verín & Payo, abad de Celanova & & \\
\hline 1189 & Orense & Alfonso IX & & Confirmación \\
\hline 1199 & Milmanda & Alfonso IX & Benavente & \\
\hline ca. 1200 & Vivero & Alfonso IX & & \\
\hline ca. 1200 & La Guardia & Alfonso IX & & \\
\hline 1201 & Bayona & Alfonso IX & & \\
\hline 1207 & Lugo & Alfonso IX & & Confirmación \\
\hline 1208 & La Coruña & Alfonso IX & Benavente & \\
\hline 1211 & Tuy & Alfonso IX & & \\
\hline 1213 & Melide & Alfonso IX & & \\
\hline ca. 1213 & Triacastela & Alfonso IX & & \\
\hline 1220 & Valle de Oro & Alfonso IX & Benavente & \\
\hline antes 1225 & Betanzos & Alfonso IX & Benavente & \\
\hline
\end{tabular}




\begin{tabular}{|c|c|c|c|c|}
\hline 1225 & $\begin{array}{l}\text { Parga } \\
\end{array}$ & Alfonso IX & Benavente & \\
\hline 1225 & Ortigueira & Alfonso IX & Benavente & \\
\hline 1225 & Lugo & Alfonso IX & & Confirmación \\
\hline 1228 & Lobera & Alfonso IX & Propio & \\
\hline 1228 & $\begin{array}{c}\text { Bonoburgo de } \\
\text { Caldelas }\end{array}$ & Alfonso IX & & Confirmación \\
\hline 1228 & Salvatierra & Alfonso IX & & \\
\hline ca. 1228 & $\begin{array}{l}\text { Villanueva de } \\
\text { Sarria }\end{array}$ & Alfonso IX & & \\
\hline 1232 & Bayona & Fernando III & & Confirmación \\
\hline 1232 & Lugo & Fernando III & & Confirmación \\
\hline 1250 & Tuy & Fernando III & & \\
\hline 1254 & Caldas de Reyes & Juan Arias, arzobispo & Propio & \\
\hline s. XIII & Noya & Juan Arias, arzobispo & Pontevedra & Renovación \\
\hline 1265 & Monterrey & Alfonso X & & \\
\hline \multirow[t]{2}{*}{1270} & Puentedeume & Alfonso X & Benavente & \\
\hline & Pontevedra & Alfonso X & & Confirmación \\
\hline 1286 & Muros & Sancho IV & Benavente & \\
\hline
\end{tabular}

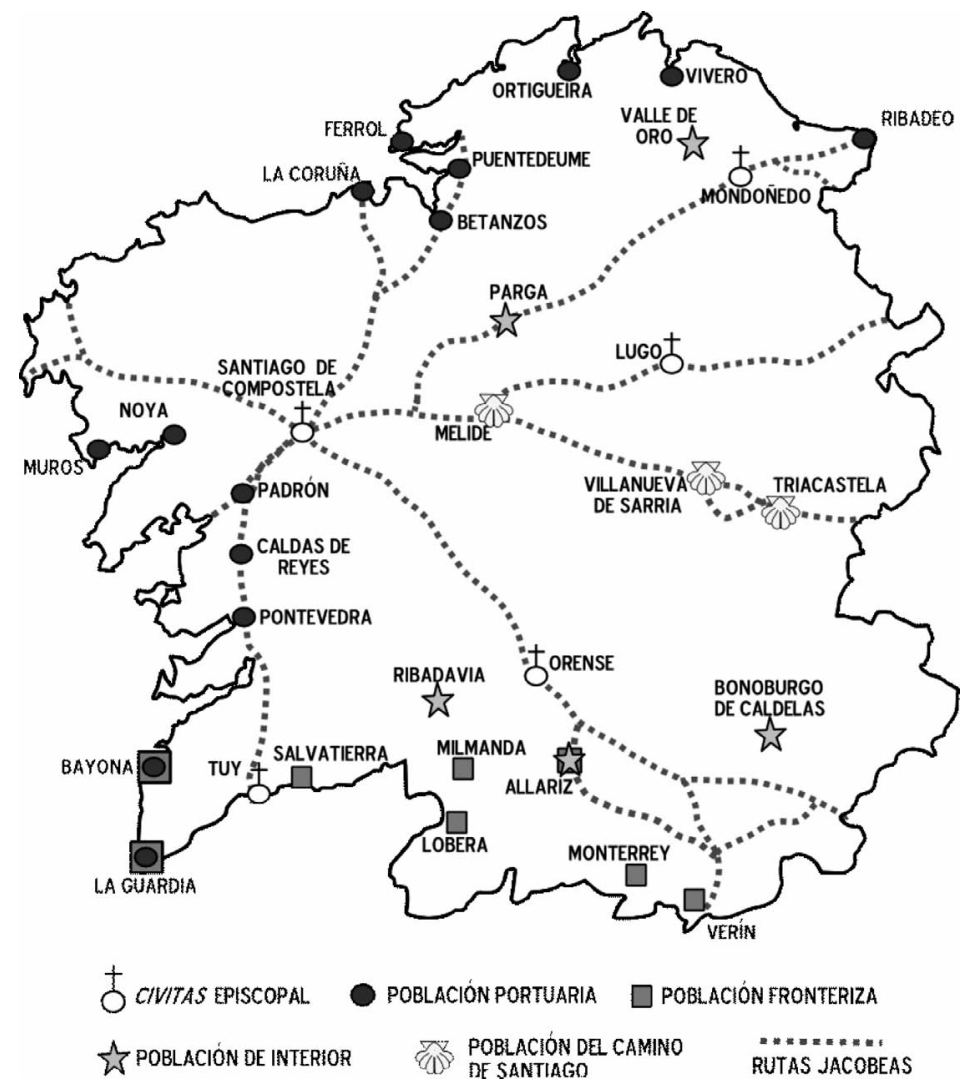

